\title{
Reactive Oxygen Species Produced by Macrophage-derived Foam Cells Regulate the Activity of Vascular Matrix Metalloproteinases In Vitro Implications for Atherosclerotic Plaque Stability
}

\author{
Sanjay Rajagopalan, Xiao Ping Meng, ${ }^{*}$ Santhini Ramasamy, David G. Harrison, and Zorina S. Galis \\ Department of Medicine, Division of Cardiology, Emory University School of Medicine, Atlanta, Georgia 30322; and the *Second Clinic \\ Hospital and the Norman Bethune University of Medical Sciences, Changchun, China 1320021
}

\begin{abstract}
Vulnerable areas of atherosclerotic plaques often contain lipid-laden macrophages and display matrix metalloproteinase activity. We hypothesized that reactive oxygen species released by macrophage-derived foam cells could trigger activation of latent proforms of metalloproteinases in the vascular interstitium. We showed that in vivo generated macrophage foam cells produce superoxide, nitric oxide, and hydrogen peroxide after isolation from hypercholesterolemic rabbits. Effects of these reactive oxygens and that of peroxynitrite, likely to result from simultaneous production of nitric oxide and superoxide, were tested in vitro using metalloproteinases secreted by cultured human vascular smooth muscle cells. Enzymes in culture media or affinitypurified (pro-MMP-2 and MMP-9) were examined by SDSPAGE zymography, Western blotting, and enzymatic assays. Under the conditions used, incubation with xanthine/ xanthine oxidase increased the amount of active gelatinases, while nitric oxide donors had no noticeable effect. Incubation with peroxynitrite resulted in nitration of MMP-2 and endowed it with collagenolytic activity. Hydrogen peroxide treatment showed a catalase-reversible biphasic effect (gelatinase activation at concentrations of $4 \mu \mathrm{M}$, inhibition at $\geq 10-50 \mu \mathrm{M})$. Thus, reactive oxygen species can modulate matrix degradation in areas of high oxidant stress and could therefore contribute to instability of atherosclerotic plaques. (J. Clin. Invest. 1996. 98:2572-2579.) Key words: atheroma • extracellular matrix degradation
\end{abstract}

\section{Introduction}

Dysregulated metabolism of extracellular matrix, principally due to focal overexpression of matrix metalloproteinases

The results described in this study have been published in abstract form (1996. Circulation. 94:A0099).

Address correspondence to Zorina S. Galis, Ph.D., Emory University School of Medicine, Division of Cardiology, 1639 Pierce Drive, WMB319, Atlanta, GA 30322. Phone: 404-727-9204; FAX: 404-727-3330; E-mail: zgalis@emory.edu

Received for publication 6 August 1996 and accepted in revised form 1 October 1996.

J. Clin. Invest.

(C) The American Society for Clinical Investigation, Inc. 0021-9738/96/12/2572/08 \$2.00

Volume 98, Number 11, December 1996, 2572-2579
(MMPs) ${ }^{1}$ may contribute to weakening of the atherosclerotic plaque (1-3). This results in plaque rupture (4), which underlies as many as $90 \%$ of acute myocardial infarctions (5). The regions of the plaques prone to rupture are the "shoulder areas," which often contain macrophages $(6,7)$. Colocalization of macrophage foam cells and active forms of MMPs within these vulnerable regions is likely relevant for disruption of atherosclerotic lesions $(1,8)$. While there is a strong connection between plaque vulnerability and the presence of macrophages $(6,7,9,10)$, the mechanisms whereby macrophages influence MMP activity remain poorly defined.

MMP regulation occurs both at the level of gene transcription (11) and activation of proenzymes (12). Several biological mediators have been noted to induce the expression of MMPs, thereby disturbing the tenuous balance between them and their endogenous inhibitors - the tissue inhibitors of MMPs or TIMPs. MMPs are secreted in a latent, zymogen form in which the prodomain is thought to fold over and shield the catalytic site. This conformation of zymogens is maintained due to thiol interactions between cysteine residues in the prodomain and the zinc atom present in the catalytic site of all MMPs. In vitro, MMP activation can occur when the prodomain is cleaved by other proteases (13-15) or when the zinc-cysteine bond is interrupted (16). Such an interruption leads to autoactivation (17). In vivo, the presence of proteolytic activators has not been established definitively in situations where MMPs are clearly active. This raises the possibility that activation by other proteases may not be necessary and that alternate pathways of MMP activation may occur in vivo.

Reactive oxygen species are known to react with thiol groups, such as those involved in preserving MMP latency, so they could modulate the activity of MMPs. The sources of reactive oxygen species in the vasculature are diverse and include vascular smooth muscle cells (SMC) (18), endothelial cells $(19,20)$ and, importantly, macrophages $(21)$. During the past several years, it has become obvious that an increase in the steady state levels of reactive oxygen species occurs in a number of pathological processes that affect the blood vessels, such as atherosclerosis (22), certain forms of hypertension (23), and diabetes mellitus $(24,25)$. We hypothesized that in areas of atherosclerotic plaques rich in macrophages activation of extracellular MMPs could occur through interaction with reactive oxygen species. Therefore, we initially defined the nature of reactive oxygen species released by lipid-laden macrophages isolated from tissues of hypercholesterolemic experi-

1. Abbreviations used in this paper: MMP, matrix metalloproteinase; MMP-2, matrix metalloproteinase-2 or gelatinase A; MMP-9, matrix metalloproteinase-9 or gelatinase B; SMC, smooth muscle cells; X/XO, xanthine/xanthine oxidase. 
mental animals. These experiments provided a basis for a rational choice of reactive oxygen species whose effects upon MMP activity were to be tested. Then, we used exogenously generated reactive oxygen species and performed in vitro experiments with latent MMPs produced by vascular SMC.

\section{Methods}

\section{Isolation of lipid-laden macrophages from experimental aortic atheroma and carrageenan-induced granuloma}

New Zealand White rabbits were fed a $0.5 \%$ cholesterol and $4.5 \%$ coconut oil diet for $9 \mathrm{wk}$. To induce granulomas, sterile 1\% carrageenan in saline was injected subcutaneously. The injection of carrageenan in hypercholesterolemic rabbits has been shown to induce the formation of macrophages which accumulate intracellular lipid and are indistinguishable from atheromatous foam cells when evaluated by scanning electron microscopy, oil red $\mathrm{O}$, and nonspecific esterase staining (26). Furthermore, the lipid metabolism and content of macrophage foam cells in granuloma or in aorta of hypercholesterolemic rabbits were found previously to be similar (27). Rabbit aortic atheroma was produced by balloon injury as described previously (28). At the end of the feeding period, the animals were killed using $100 \mathrm{mg} / \mathrm{ml}$ pentobarbital.

Lipid-laden, macrophage-derived foam cells were isolated from aortic atheromas and subcutaneous granulomas. Briefly, the aorta and the granulomas were separately harvested, minced, and then incubated under sterile conditions with HBSS containing collagenase (type I; Worthington Biochemical Corp., Freehold, NJ), elastase, and soybean trypsin inhibitor (Sigma Chemical Co., St. Louis, MO) (28). The resultant turbid fluid was filtered through a sterile nylon mesh filter and cells were collected in sterile tubes. Foam cells were then isolated by metrizamide density centrifugation as described previously $(28,29)$. Aliquots of cells were resuspended in Opti-MEM (Gibco Laboratories, Grand Island, NY) and used for cell counting and measurement of reactive oxygen species. The presence of intracellular lipid was confirmed by intense Nile red (Molecular Probes, Inc., Eugene, OR) staining of the cytoplasm.

To study non-lipid-laden macrophages, we obtained alveolar macrophages by bronchoalveolar lavage in the same rabbits. After anesthesia, but before death, the trachea was cannulated with sterile plastic tubing $(4 \mathrm{~mm})$ and gently lavaged twice with $25 \mathrm{~cm}^{3}$ of sterile normal saline. The lavages were then centrifuged and pelleted out at $500 \mathrm{~g}$ for $5 \mathrm{~min}$. The alveolar macrophages were resuspended in OptiMEM and then subjected to the same handling procedures as the foam cells (i.e., enzymatic digestion, centrifugation) to check for the possible effect of the isolation protocol on reactive oxygen species production.

The protocol for animal use has been approved by the Emory University Committee on Institutional Animal Care and Use.

\section{SMC culture}

SMC were grown from explants of human saphenous veins obtained at bypass surgery. Cells from passages 3 to 4 were grown to confluency in DME (Cellgro/Fisher, Herndon, VA) containing an antibioticantimycotic mixture (penicillin $100 \mathrm{U} / \mathrm{ml}$; streptomycin $100 \mathrm{mg} / \mathrm{ml}$; amphotericin B: $0.25 \mathrm{mg} / \mathrm{ml}$; Cellgro/Fisher) and supplemented with $10 \%$ FCS. Cells were then washed twice with HBSS and transferred into serum-free medium (DME/F12; 1:1), supplemented with $1 \mathrm{mM}$ insulin and $5 \mu \mathrm{g} / \mathrm{ml}$ transferrin, for $24 \mathrm{~h}$ at the end of which SMC-conditioned culture media containing pro-MMP-2 were harvested. In some experiments, SMC were incubated for $24 \mathrm{~h}$ with PMA $(100 \mathrm{ng} / \mathrm{ml}$, Sigma Chemical Co.) for induction of pro-MMP-9.

\section{Affinity purification of MMPs}

MMP-2 and -9, also called gelatinases due to their activity toward gelatin, can be isolated based on their affinity for this substrate. Briefly, $1 \mathrm{ml}$ of SMC-conditioned culture medium from unstimulated cells or cells stimulated with PMA (to induce secretion of MMP-9) was added to $100 \mu \mathrm{l}$ gelatin-agarose beads (Sigma Chemical Co.) and the mixture was incubated for $1 \mathrm{~h}$ at $4^{\circ} \mathrm{C}$. The mixture was then centrifuged briefly, washed, and the gelatinases were eluted from the agarose by adding $100 \mu \mathrm{l}$ cold $10 \%$ DMSO. The mixture was incubated for $5 \mathrm{~min}$ and pulse-centrifuged, after which the supernatant containing the eluted gelatinases was loaded onto polysulfone ultrafuge filters (30,000 NMWC; Micron Separations Inc., Westboro, MA) and centrifuged again for $5 \mathrm{~min}$ at 3,500 rpm to remove DMSO. The filtered supernatant (containing the MMPs) was subsequently used to study activity of MMP-2 and -9.

\section{Cell-free incubation experiments}

In cell-free experiments, we tested the effect of reactive oxygen species on MMPs present either in the conditioned culture medium harvested from SMC or affinity-purified MMPs. Incubations were carried out in a total volume of $500 \mu \mathrm{l}$ for times ranging from $30 \mathrm{~min}$ to $24 \mathrm{~h}$. To generate $\mathrm{O}_{2}^{-{ }^{-}}$and $\mathrm{H}_{2} \mathrm{O}_{2}$, we used mixtures of xanthine and xanthine oxidase $(\mathrm{X} / \mathrm{XO})$. In most experiments, culture media or purified gelatinases were incubated with $100 \mu \mathrm{M}$ xanthine and $5 \mathrm{mU} / \mathrm{ml}$ xanthine oxidase (Sigma Chemical Co.). Under these conditions, $16.52 \mu \mathrm{M} \mathrm{O}_{2}^{-}{ }^{-}$was generated, as measured by lucigenin chemiluminescence. In other experiments, similar samples were incubated with $\mathrm{H}_{2} \mathrm{O}_{2}$ (Sigma Chemical Co.), at final concentrations varying from 4 to $50 \mu \mathrm{M}$. To examine the effect of nitric oxide, we used the NO donors, $S$-nitroso- $N$-acetyl-D, L penicillamine (SNAP) or SPER/NO, (Z)-1( $N$-[3-aminopropyl]- $N$-[4-(3-amino-propylammonio)butyl]-amino)-diazen-1-ium-1,2-diolate] (Spermine NONO-ate) (Research Biochemicals Inc., Natick, MA) at 50-500 $\mu \mathrm{M}$. Peroxynitrite anion $\left(\mathrm{ONOO}^{-}\right.$, purchased as a $0.17 \mathrm{M}$ stock in $0.3 \mathrm{M} \mathrm{NaOH}$; Alexis Corp., San Diego, CA) was also added directly to culture medium (final concentration of $10-500 \mu \mathrm{M})$. The effect of adding the highest volume of $0.3 \mathrm{M}$ $\mathrm{NaOH}$ (vehicle corresponding to the highest concentration of $\mathrm{ONOO}^{-}$) to the samples was also examined. Since $\mathrm{H}_{2} \mathrm{O}_{2}$ and $\mathrm{ONOO}^{-}$were not continuously generated and have a short life time, we added repetitive equal doses of these reactive oxygen species in some experiments. At the end of each incubation, samples were directly loaded on to gels for SDS-PAGE zymography or Western blotting.

\section{SDS-PAGE zymography}

Proteins with gelatinolytic activity were identified by electrophoresis in the presence of SDS in $10 \%$ discontinuous polyacrylamide gels containing $1 \mathrm{mg} / \mathrm{ml}$ gelatin. In this method, after electrophoretic migration, proteins with gelatinolytic activity can be detected due to their capacity to digest the gelatin substrate incorporated into SDSPAGE gels. Culture media were loaded on gels directly or after affinity purification. The proteins in the gels were renatured by exchanging SDS with Triton X-100 (two 15-min incubations with $2.5 \%$ Triton $\mathrm{X}-100$ ). The gels were subsequently incubated overnight at $37^{\circ} \mathrm{C}$ in 50 $\mathrm{mM}$ Tris- $\mathrm{HCl}, \mathrm{pH} 7.4$, containing $10 \mathrm{mM} \mathrm{CaCl}_{2}$ and $0.05 \%$ Brij 35. At the end of the incubation, gels were stained with Colloidal Brilliant Blue G (Sigma Chemical Co.). Proteins having gelatinolytic activity were then visualized as areas of lytic activity on an otherwise blue gel. Migration of proteins was compared with that of prestained low molecular weight range markers (Bio-Rad, Hercules, CA). Identical gels were incubated in parallel in the presence of 0.01 M EDTA. Disappearance of lytic bands in these gels confirmed the metal dependence of gelatinolytic activity characteristic of MMPs. Photographs of the gel were scanned by an imaging densitometer and quantified using the NIH Image 1.55 software program.

\section{Enzymatic assays}

The type IV collagenase activity of SMC-conditioned culture medium after incubation with different reactive oxygen species was detected using ${ }^{3} \mathrm{H}$-collagen type IV (Du Pont-NEN, Wilmington, DE). Aliquots $(50$ and $100 \mu \mathrm{l})$ of either treated or untreated SMC culture medium were incubated with $2 \mu \mathrm{g}{ }^{3} \mathrm{H}$-collagen IV (specific activity 0.14 $\mathrm{mCi} / \mathrm{mg}$ ). Some samples were incubated with treatments alone (reac- 
tive oxygen species or reactive oxygen species-generating systems) to test their direct effect upon degradation of collagen IV. All samples were incubated at $37^{\circ} \mathrm{C}$ for $18 \mathrm{~h}$, then reactions were stopped by addition of reducing SDS-PAGE sample buffer and samples were boiled for $10 \mathrm{~min}$ and loaded onto $10 \%$ SDS-polyacrylamide gels. Degradation of radiolabeled collagen was assessed by fluorography of gels dried after impregnation with $\mathrm{EN}^{3} \mathrm{HANCE}$ (DuPont-NEN).

\section{Western blotting}

SMC culture media were separated on $10 \%$ SDS-PAGE mini gels and transferred onto nitrocellulose membranes (Bio-Rad), using a semidry blotting system (Bio-Rad). Blocking of nonspecific binding was achieved with incubation of the membrane in $5 \%$ milk in $50 \mathrm{mM}$ Na phosphate buffer, $\mathrm{pH} 7.2,150 \mathrm{mM}$ Na chloride (PBS) containing $0.1 \%$ Tween 20 . Rabbit polyclonal antibodies to MMP-2 were obtained from Dr. William Stetler-Stevensen (National Institutes of Health, Bethesda, MD). Monoclonal antibodies against nitro-tyrosine were kindly provided by Dr. Joseph S. Beckman (University of Alabama at Birmingham). Antigen detection was performed with a chemiluminescent detection system as per the manufacturer's instructions (ECL ${ }^{\mathrm{TM}}$, Amersham International, Buckinghamshire, UK).

\section{Reactive oxygen species produced by macrophages}

$\mathrm{O}_{2}{ }^{-}$production. $\mathrm{O}_{2}^{-}$production by macrophages was measured by lucigenin chemiluminescence. Lucigenin is a sensitive and specific

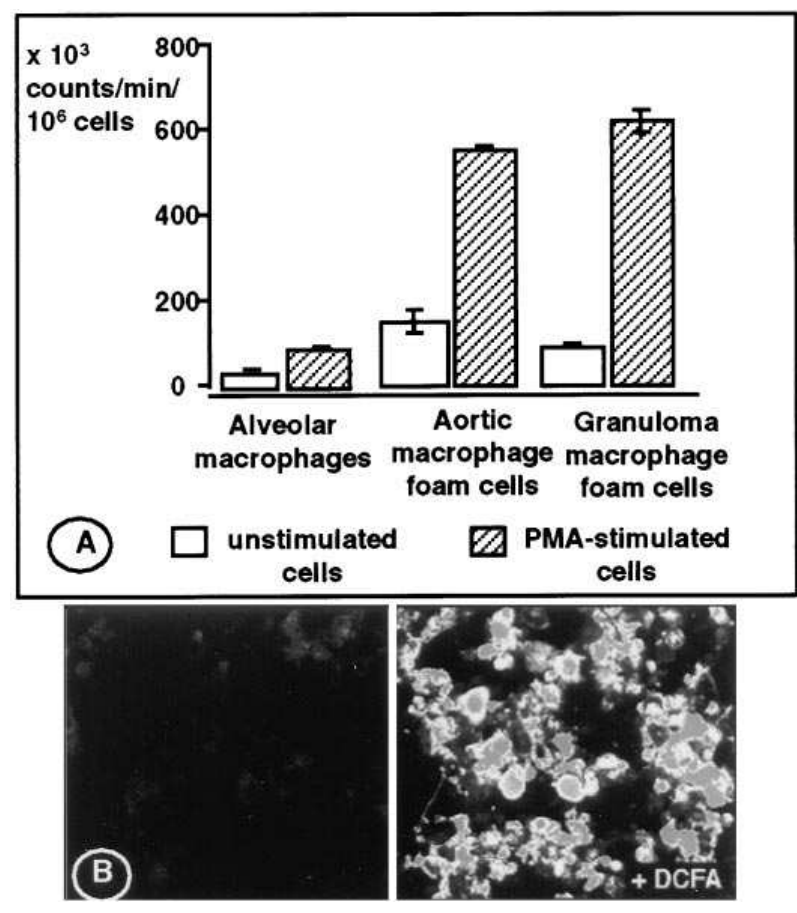

Figure 1. (A) Lucigenin-enhanced chemiluminescence, reflecting production of superoxide by alveolar macrophages, aortic foam cells, and granuloma foam cells isolated from cholesterol-fed rabbits. Unstimulated cells as well as cells stimulated with PMA were assayed. The figure shows the average of triplicate measurements of steady state levels of chemiluminescence $15 \mathrm{~min}$ after adding cells to the lucigenin-containing buffer. In this assay, $10 \mathrm{pmol}$ of $\mathrm{O}_{2}^{-}$generated from known amounts of xanthine and xanthine oxidase yielded $\sim 4,700$ counts. (B) Detection of hydroperoxides as shown by the fluorescence of DCF in lipid-laden macrophages. The left panel shows the autofluorescence of cells incubated in the absence of DCFA and the right panel shows cells 30 min after addition of DCFA. Cells were imaged with a confocal microscope using a magnification of 40 and an FITC filter. measure of $\mathrm{O}_{2}^{-}$release (30). Details of this assay have been published previously $(20,22)$. Scintillation vials containing $250 \mathrm{mM}$ lucigenin solution in $50 \mathrm{mM}$ phosphate buffer $(\mathrm{pH} 7.4)$ were placed in a scintillation counter in the out-of-coincidence mode and allowed to dark adapt for 4 min to obtain background counts. After counting the number of cells, $10^{6}$ macrophages were suspended in $50 \mathrm{mM}$ phosphate buffer and added to the vial containing lucigenin. Counts were obtained at 1-min intervals for $12 \mathrm{~min}$. Steady state counts corrected for the background values were then expressed as counts $/ 10^{6}$ cells/ min. To study the effect of exogenous stimuli, macrophages were incubated with PMA (final concentration $100 \mu \mathrm{M}$ ) for 5 min before measurement of $\mathrm{O}_{2}^{-}$.

Measurement of $N O$ synthase activity by conversion of $\left.L-1{ }^{14} C\right]$ arginine to $\mathrm{L}-\left[{ }^{14} \mathrm{C}\right]$ citrulline. Freshly isolated macrophages were homogenized in the presence of protease inhibitors $(1 \mathrm{mM}$ pepstatin $\mathrm{A}, 2 \mathrm{mM}$ leupeptin, $1 \mathrm{mM}$ bestatin, and $1 \mathrm{mM}$ PMSF). NO synthase activity was assayed in the particulate fraction of the homogenate. Each sample, normalized by protein $(100 \mu \mathrm{g})$, was incubated in the presence of cofactors [final concentration: $100 \mathrm{nM}$ calmodulin, $2.5 \mathrm{mM} \mathrm{CaCl}_{2}, 1$ $\mathrm{mM}$ NADPH, $3 \mathrm{mM}$ tetrahydrobiopterin] and the substrate $100 \mathrm{mM} /$ liter L-arginine combined with $\mathrm{L}-\left[2,3-{ }^{3} \mathrm{H}\right]$ arginine $(0.2 \mathrm{mCi}$; specific activity, $55 \mathrm{Ci} / \mathrm{mmol}$ ) for $15 \mathrm{~min}$ at $37^{\circ} \mathrm{C}$. The mixture also contained 1 $\mathrm{mM}$ L-citrulline to minimize any conversion of the formed L-[2,3$\left.{ }^{3} \mathrm{H}\right]$ citrulline back to L- $\left[2,3-{ }^{3} \mathrm{H}\right]$ arginine (31). After the incubation period, the reaction was quenched by addition of $1 \mathrm{ml}$ of stop buffer (20 mM Hepes, $\mathrm{pH}$ 5.5; 2 mM EDTA, and 2 mM EGTA). The reaction mix was applied to a $1-\mathrm{ml}$ column that had been preequilibrated with the stop buffer. Radioactivity associated with $\mathrm{L}-\left[2,3-{ }^{3} \mathrm{H}\right]$ citrulline was eluted twice from a Dowex AG 50WX-8 column ( $\mathrm{Na}^{+}$form, Bio$\mathrm{Rad})$ and measured by liquid scintillation counting.

Detection of $\mathrm{H}_{2} \mathrm{O}_{2}$ production by 2,7-dichlorofluorescein (DCF) fluorescence. This test is based on the $\mathrm{H}_{2} \mathrm{O}_{2}$-mediated conversion of 2,7-dichlorofluorescein diacetate (DCFA; Molecular Probes, Inc.) into fluorescent DCF, with increased fluorescence emission reflecting enhanced $\mathrm{H}_{2} \mathrm{O}_{2}$ production (32). Briefly foam cells in tissue culture dishes were loaded with $10 \mathrm{mM}$ DCFA by incubation for 30 minutes. Before analysis, cells were washed two times with PBS and then imaged by confocal scanning laser microscopy using $488 \mathrm{~nm}$ excitation and $510 \mathrm{~nm}$ emission filters.

\section{Results}

Reactive oxygen species production in lipid-laden macrophages Superoxide production. We found that lipid-laden macrophages isolated from either atherosclerotic aortas or granulomas of hypercholesterolemic rabbits generated $\mathrm{O}_{2}^{-}$(Fig. $1 A$ ). Counts reflecting $\mathrm{O}_{2}^{-}$production were higher in lipid-laden macrophages than those generated by non-lipid-laden alveolar macrophages from the same animals (e.g., Fig. $1 A$, steady state chemiluminescence levels of $153.7 \pm 13.0$ and $81.1 \pm 5.2$ from foam cells vs. $31.7 \pm 5.6 \times 10^{3}$ counts $/ \mathrm{min} / 10^{6}$ alveolar macrophages, respectively). Interestingly, aortic foam cells, in the absence of exogenous stimulation, produced even more $\mathrm{O}_{2}^{-}{ }^{-}$than alveolar macrophages stimulated with PMA $\left(153.7 \pm 13.0\right.$ vs. $86.0 \pm 4.3 \times 10^{3}$ counts $/ \mathrm{min} / 10^{6}$ cells, respectively). The level of $\mathrm{O}_{2}^{-{ }^{-}}$production was increased severalfold by PMA stimulation in both aortic (from $153.7 \pm 13.0 \times 10^{3}$ counts $/ \mathrm{min} / 10^{6}$ cells to $561.5 \pm 9.0 \times 10^{3}$ counts $/ \mathrm{min} / 10^{6}$ cells $)$ and in granuloma-derived foam cells (from 81.1 \pm 5.2 to $616.4 \pm 25.0 \times 10^{3}$ counts $/ \mathrm{min} / 10^{6}$ cells), suggesting a high oxidative potential.

NOS activity. NOS activity in foam cells from several granulomas was highly variable. In some, as little as $0.26 \pm 0.03$ $\mathrm{pmol} / \mathrm{mg}$ protein $/ \mathrm{min}$ of ${ }^{3} \mathrm{H}$-citrulline was detected, while in others as much as $4.7 \mathrm{pmol} / \mathrm{mg}$ protein $/ \mathrm{min}$ of ${ }^{3} \mathrm{H}$-citrulline was 


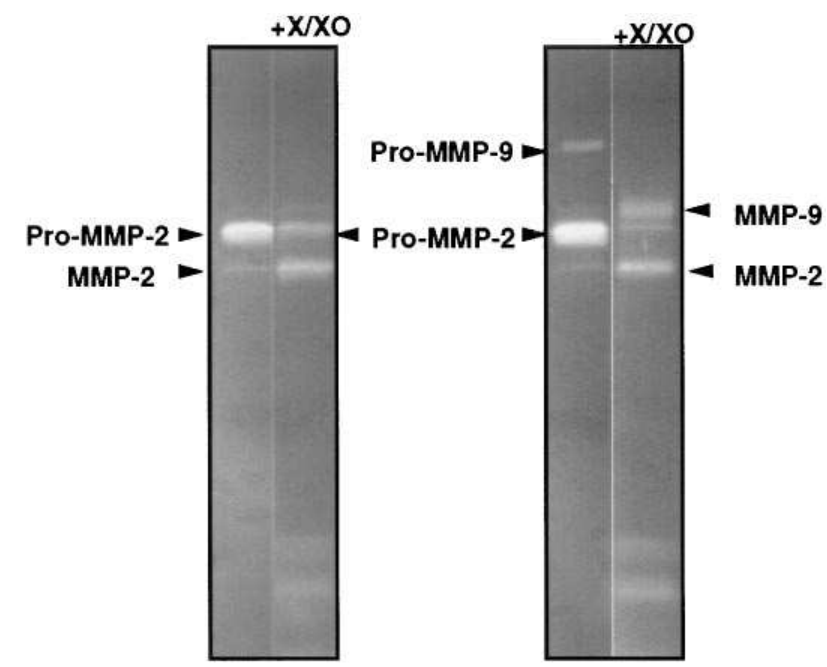

Figure 2. SDS-PAGE zymography showing the effect of reactive oxygen species generated by X/XO $(100 \mu \mathrm{M}: 5 \mathrm{mU} / \mathrm{ml})$ on activity of latent gelatinases, which were affinity-purified from culture medium harvested from human vascular SMC. White areas of lysis produced in the gel, which contained $1 \mathrm{mg} / \mathrm{ml}$ gelatin, shows presence of activated, as well as latent, forms of gelatinases. The left panel illustrates activation of latent MMP-2 (pro-MMP-2), purified from the conditioned medium of unstimulated human SMC, after incubation with $\mathrm{X} / \mathrm{XO}$. The right panel shows activation of pro-MMP-2 and latent MMP-9 (pro-MMP-9) isolated from medium of SMC stimulated with PMA (which induces MMP-9 expression). Treatment with X/XO resulted in the conversion of latent forms of both gelatinases to the active, lower molecular weight forms (MMP-2 and MMP-9).

formed. In each preparation NOS activity was not affected by addition of EGTA (average ${ }^{3} \mathrm{H}$-citrulline in the presence of EGTA was $0.82 \pm 0.30 \mathrm{pmol} / \mathrm{mg}$ protein $/ \mathrm{min}$ ), suggesting that the NO synthase responsible for this activity was the inducible isoform. Due to limited cell yield for aortic foam cells, we measured formation of ${ }^{3} \mathrm{H}$-citrulline only in a pair of samples ob- tained from one experiment, in which cells from four rabbits were pooled. This was $1.32 \mathrm{pmol} / \mathrm{mg}$ protein/min. Alveolar macrophages isolated from the same rabbits had no detectable NO synthase activity.

$\mathrm{H}_{2} \mathrm{O}_{2}$ detection. Lipid-laden macrophages cultured for $24 \mathrm{~h}$, then incubated with DCFA $(10 \mu \mathrm{M})$, showed intense fluorescent staining by confocal microscopy, indicative of peroxide generation (Fig. $1 B$ ).

\section{Effect of reactive oxygen species on vascular MMP activity in vitro}

$X / X O$ system activates latent MMPs. Incubation of human vascular SMC culture media containing latent MMP-2 (proMMP-2) with X/XO (100 $\mu$ M:5 U/liter) resulted in activation of pro-MMP-2. Activation also occurred when culture media were incubated with $\mathrm{X} / \mathrm{XO}$ after harvesting from tissue culture dishes. To rule out the contribution of other components in the culture media that could serve as intermediaries in this activation sequence, latent MMP-2 and MMP-9 (induced by PMA treatment of vascular SMC) were purified using gelatin-agarose. The purified gelatinases were then exposed to the $\mathrm{X} / \mathrm{XO}$ system, which led again to activation of pro-MMP-2 as well as pro-MMP-9 (Fig. 2). Fig. 2 presents the typical appearance of gelatinolytic bands with lower molecular weights after incubation with X/XO. XO by itself had no effect upon latent MMP-2 (data not shown), but was responsible for production of lytic bands that migrate close to the bottom of $10 \%$ gels (Fig. 2) and are not inhibited by incubation with EDTA. Xanthine neither affected pro-MMP-2 nor produced any lytic pattern in gelatin gels, suggesting that pro-MMP-2 activation was due to a product of the $\mathrm{X} / \mathrm{XO}$ system. In additional experiments, we tested the effect of adding SOD to the incubates (not shown), but activation of pro-MMP-2 by X/XO was not inhibited, probably due to the simultaneous generation of other reactive oxygen species $\left(\mathrm{H}_{2} \mathrm{O}_{2}\right.$ and/or hydroxyl, $\left.\cdot \mathrm{OH}\right)$.

Effect of $\mathrm{H}_{2} \mathrm{O}_{2}$ on MMP-2 activity. $\mathrm{H}_{2} \mathrm{O}_{2}$ is likely produced by lipid-laden macrophages in vivo. In vitro, $\mathrm{H}_{2} \mathrm{O}_{2}$ is a main product of the $\mathrm{X} / \mathrm{XO}$ system, which we used to generate reactive oxygen species in vitro, and thus could have contrib-

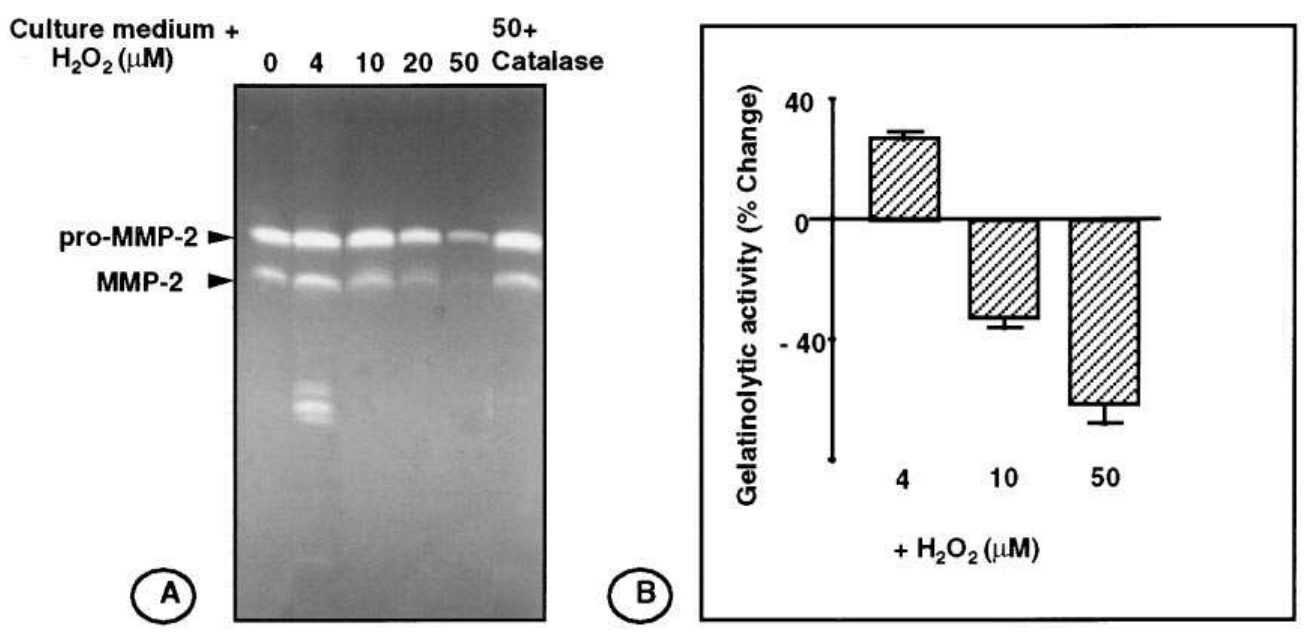

Figure 3. (A) SDS-PAGE zymography of media conditioned by human SMC. Identical aliquots were exposed to various concentrations of $\mathrm{H}_{2} \mathrm{O}_{2}$ for $4 \mathrm{~h}$. The upper arrow points to the latent form of MMP-2 (proMMP-2). Notice that incubation with $4 \mu \mathrm{M} \mathrm{H}_{2} \mathrm{O}_{2}$ activated proMMP-2 to the lower molecular weight active form MMP-2 (lower arrow) and even to smaller forms with gelatinolytic activity. Higher doses of $\mathrm{H}_{2} \mathrm{O}_{2}$ led to inactivation (disappearance of gelatinolytic activity). The effect of the highest concentration of $\mathrm{H}_{2} \mathrm{O}_{2}(50 \mu \mathrm{M})$ was prevented by addition of cata-

lase $(250 \mathrm{U} / \mathrm{ml}) .(B)$ Effect of $\mathrm{H}_{2} \mathrm{O}_{2}$ upon the gelatinolytic activity associated with the active form of MMP-2, as measured from SDS-PAGE zymography gels. Areas of lysis have been measured by laser scanning densitometry and plotted as the percentage of gelatin lysis produced by control. Data shown have been collected from four independent experiments. Compared with control samples ( $\left(\right.$ o $\mathrm{H}_{2} \mathrm{O}_{2}$ ), gelatinolytic activity was increased by incubation with $4 \mu \mathrm{M} \mathrm{H}_{2} \mathrm{O}_{2}$, and decreased by incubation with $50 \mu \mathrm{M}$. 


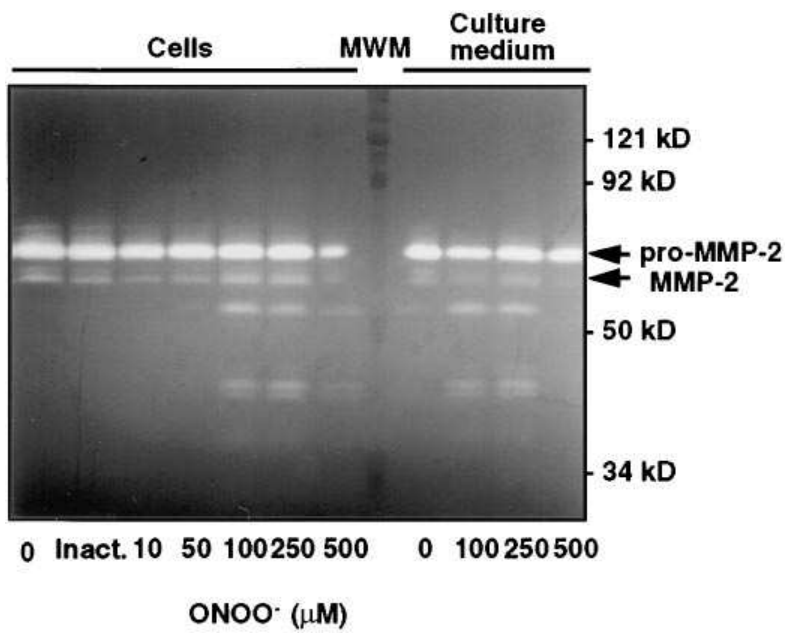

Figure 4. Effect of peroxynitrite on gelatinolytic activity in culture media of human SMC. In left lanes, we applied culture media from SMC incubated with increasing concentrations of $\mathrm{ONOO}^{-}$for $24 \mathrm{~h}$. One cell culture dish was incubated with the highest concentration of $\mathrm{pH}$-inactivated $\mathrm{ONOO}^{-}$(Inact.). The right lanes show activity in media harvested from unstimulated SMC, then incubated with similar concentrations of $\mathrm{ONOO}^{-}$. The same gelatinolytic pattern was obtained in both cases $( \pm$ SMC). Molecular weight of prestained markers $(M W M)$, loaded in between samples obtained from the two experiments, is indicated at right in kiloDaltons $(\mathrm{kD})$.

uted to the activation of MMP-2 that we observed using X/XO. The direct effect of $\mathrm{H}_{2} \mathrm{O}_{2}$ on pro-MMP-2 activity was tested by incubating aliquots of cell culture media with various concentrations of $\mathrm{H}_{2} \mathrm{O}_{2}$. At low concentrations, incubation with $\mathrm{H}_{2} \mathrm{O}_{2}$ increased gelatinolysis associated with the activated form of MMP-2 and also induced generation of lower molecular weight gelatinolytic bands (Fig. $3 A$ ). Higher doses of $\mathrm{H}_{2} \mathrm{O}_{2}$ $(10-50 \mu \mathrm{M})$ resulted in concentration-dependent inactivation of gelatinolytic activity (Fig. 3, $A$ and $B$ ). The effects of $\mathrm{H}_{2} \mathrm{O}_{2}$ could be blocked completely by addition of catalase (Fig. $3 A$ ). We confirmed that $\mathrm{H}_{2} \mathrm{O}_{2}$ initiates molecular processing of latent MMP-2 by identifying the lower molecular species with anti-MMP-2 antibodies (shown in Fig. 6). Compared with control culture media, aliquots incubated with $\mathrm{H}_{2} \mathrm{O}_{2}$ displayed increased immunoreactivity of lower molecular weight species and additional immunoreactive bands.

Effect of $\cdot \mathrm{NO}$ and peroxynitrite $\left(\mathrm{ONOO}^{-}\right)$on $\mathrm{MMP}-2$ activity. Generation of NO by SNAP and Spermine NONO-ate $(50-500 \mu \mathrm{M})$ in the culture media had no discernible effect upon activation of MMP-2 zymogen (data not shown). However, since the simultaneous production of $\mathrm{NO}$ and $\mathrm{O}_{2}^{-}$in vivo may lead to the generation of $\mathrm{ONOO}^{-}$(33), we also tested the effect of this reactive oxygen species upon MMP-2 produced by cultured vascular SMC. We incubated cells in culture with $\mathrm{ONOO}^{-}$and analyzed culture media by SDS-PAGE zymography. We found that after incubation with $\mathrm{ONOO}^{-}$the intensity of the MMP-2-associated lytic band, migrating at $\sim 60 \mathrm{kD}$, was increased and was accompanied by the appearance of several lower molecular weight gelatinolytic bands (Fig. 4). Initially, we suspected that in addition to activation of pro-MMP-2, incubation of SMC with $\mathrm{ONOO}^{-}$may induce the production and release of new proteins with gelatinolytic activity. However, the same effect was achieved by incubating the

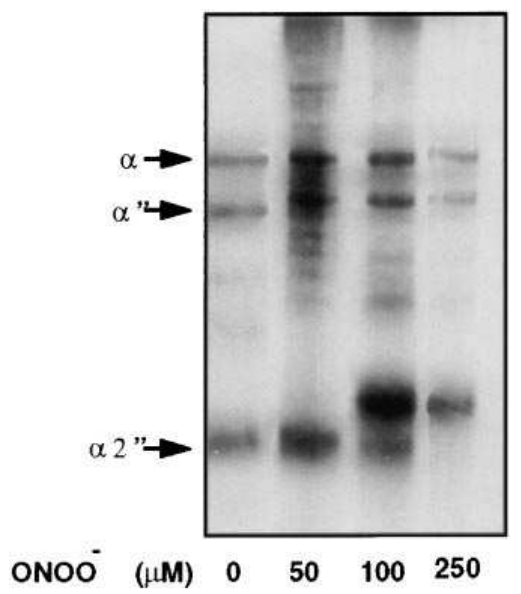

Figure 5. Fluorographic image of ${ }^{3} \mathrm{H}$-type IV collagen incubated with SMC-conditioned medium treated with $\mathrm{ONOO}^{-}$. Typical collagen bands are indicated with arrows.

Treatment with

$\mathrm{ONOO}^{-}$imparts collagenolytic activity to SMC-derived culture media, as suggested by the diminishing radioactivity associated with $\alpha 2$ " chains and proteolytic processing of other higher molecular weight collagen chains.

culture media after harvesting from unstimulated SMC (cellfree experiments) with $\mathrm{ONOO}^{-}$(Fig. 4). This showed that the generation of several gelatinolytic bands running at apparent molecular masses $<60 \mathrm{kD}$ did not require the presence of cells and was likely due to sequential extracellular processing of MMP-2. Additional confirmation that incubation with $\mathrm{ONOO}^{-}$results in activation of latent MMP-2 was obtained through a collagenolytic assay using radiolabeled type IV collagen, a typical MMP-2 substrate. Latent MMP-2 incubated with $\mathrm{ONOO}^{-}$displayed enzymatic activity against collagen IV (Fig. 5). Culture media incubated with $\mathrm{pH}$-inactivated $\mathrm{ONOO}^{-}$, containing the stable decomposition products $\mathrm{NO}_{2}^{-}$ and $\mathrm{NO}_{3}{ }^{-}$, had no collagenolytic activity. The activation of proMMP-2 by $\mathrm{ONOO}^{-}$was accompanied by tyrosine nitration of MMP-2 (Fig. 6), as shown by consecutive immunodetection of MMP-2 followed by detection of nitro-tyrosine residues in samples of SMC culture media. Incubation of culture media

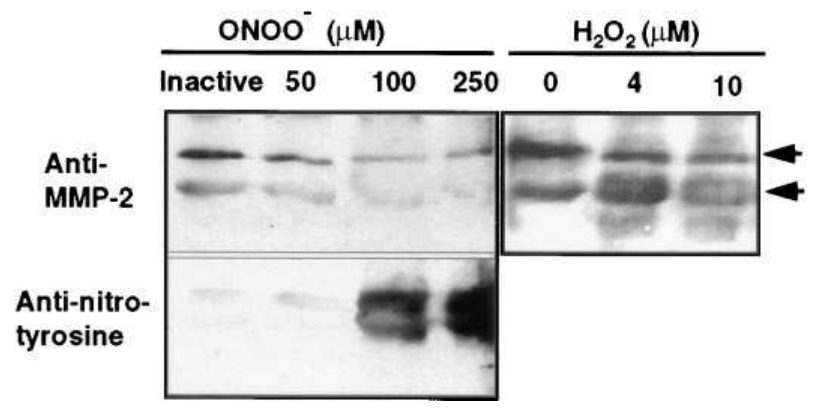

Figure 6. Immunoblotting of SMC culture media incubated with peroxynitrite $\left(\mathrm{ONOO}^{-}\right)$or $\mathrm{H}_{2} \mathrm{O}_{2}$. The top panels show detection of latent MMP-2 (top arrow) and activated MMP-2 (bottom arrow). The bottom left panel shows detection of nitrotyrosine residues using specific antibodies. The membrane containing $\mathrm{ONOO}^{-}$-treated culture media, presented in the left two panels, was first blotted with antiMMP-2 antibodies (top left panel), then stripped, and reprobed with antinitrotyrosine antibodies (bottom left panel). Incubation with $\mathrm{ONOO}^{-}$led to a decrease in immunoreactivity to MMP-2 antibodies and to an increased immunoreactivity to antinitrotyrosine antibodies. In contrast incubation of culture media with $\mathrm{H}_{2} \mathrm{O}_{2}$ actually increased the signal associated with activated MMP-2 (bottom arrow), as detected by anti-MMP-2 antibodies. 
with $100-250 \mu \mathrm{M}$ of $\mathrm{ONOO}^{-}$abolished the immunoreactivity of the anti-MMP-2 antibody for bands associated with activated forms of MMP-2, while increasing the immunoreactivity of antinitrotyrosine antibodies for the corresponding bands. This effect suggested that, during activation, the MMP-2 epitopes recognized by the MMP- 2 antibody were modified by nitration. Further supporting the hypothesis of a specific modification of MMP-2 by $\mathrm{ONOO}^{-}$treatment was the finding that the same anti-MMP-2 antibody recognized an MMP-2 form activated by $\mathrm{H}_{2} \mathrm{O}_{2}$ (Fig. 6).

\section{Discussion}

This study was undertaken to examine the possibility that reactive oxygen species produced by lipid-laden macrophages modulate vascular MMP activity. We found that macrophage foam cells, isolated from atheroma, steadily produce $\mathrm{O}_{2}^{-{ }^{-}}$, $\mathrm{H}_{2} \mathrm{O}_{2}$, and $\mathrm{NO}$ without additional exogenous stimulation. We also showed that these reactive oxygens can modulate MMP-2 and -9 activity, either directly or via a derivative radical, $\mathrm{ONOO}^{-}$. This may be an important mechanism for modulating MMP activity in atherosclerotic plaques. Similar radicals may also be responsible for MMP activation in inflammation or other conditions associated with oxidative stress.

Traditionally, the theory regarding MMP activation in vivo postulates the attack of susceptible regions in the propeptide MMP domain by soluble proteases (13), or by a membranebond protease in the case of MMP-2 $(34,35)$. Studies from Van Wart's group (16) led to the formulation of the "cysteineswitch" hypothesis to explain the seemingly disparate means by which activation could be achieved in vitro by a wide variety of agents that share one common characteristic: thiol reactivity. In this model, the zinc atom at the active site is coordinately bound to an unpaired cysteine thiol group located approximately at the $80^{\text {th }}$ residue of the propeptide domain. Disruption of this interaction is believed to represent the critical step in initiating the process of MMP autoactivation. Reactive oxygen species undergo facile reactions with thiol groups and may serve as a common mechanism of activation for several different MMPs. Macrophage-derived reactive oxygen species may thus provide a link between the presence of activated forms of MMPs and macrophage-rich areas in atherosclerotic plaques.

Rosenfeld et al. showed previously that macrophage-derived foam cells isolated from hypercholesterolemic rabbit aortas are capable of oxidatively modifying lipoproteins (29), but the nature of reactive oxygen species released by these cells has not been defined. To our knowledge, all other previous studies have examined reactive oxygen species production by monocytes differentiated in vitro and subsequently activated with exogenous stimuli. Properties of cells differentiated and loaded with lipid in vitro may differ significantly from foam cells generated in vivo. In this study, we examined two types of macrophages that accumulate lipid in vivo, in tissues of hypercholesterolemic animals. By producing lipid-laden macrophages in granulomas we have generated large quantities of foam cells for study, in contrast to aortic foam cells isolated from atheroma, where the yield of isolated cells is low. Further, rapid isolation ( $<4 \mathrm{~h}$ from time of killing of the animal) precludes the influence of extraneous factors that may influence radical production.

Macrophage foam cells, whether derived from aortic ather- oma or granuloma of hypercholesterolemic animals, produced substantial amounts of superoxide compared with non-lipidladen macrophages obtained from the same animal. Lipid-laden macrophages expressed varying amounts of NO synthase activity. In contrast, NO synthase activity was undetectable in alveolar macrophages. These findings provided a basis for experiments testing the effects of $\mathrm{O}_{2}^{-}, \mathrm{H}_{2} \mathrm{O}_{2}, \mathrm{NO}$, and $\mathrm{ONOO}^{-}$ on activity of vascular MMPs. To directly examine the effects of these, we either generated or exogenously added the various reactive oxygen species of interest. MMPs investigated were produced by cultured human SMC. These cells can produce a spectrum of MMPs (36) and likely contribute substantially to the MMPs produced in human vessels.

We concentrated on vascular gelatinases for two reasons. First, MMP-2 is ubiquitous in normal and atherosclerotic human vessels (1) and is produced in vitro by vascular human endothelium (37) and SMC (36). Generation of activated forms of MMP-2 is associated with SMC migration and proliferation in vitro and in vivo in animal models of restenosis (38-41). Induction of MMP-9 also occurs under these conditions (38-41). Pro-MMP-9, the main MMP product of monocyte-macrophages (42), is expressed in human atheroma (1) and can be detected in specimens collected from patients with unstable angina (43). Second, the biochemical characteristics of these two gelatinases, which have prodomains rich in cysteine residues, would presumably increase their susceptibility to the action of reactive oxygen species.

The $\mathrm{X} / \mathrm{XO}$ reaction, commonly used to generate $\mathrm{O}_{2}^{-{ }^{-}}$, also generates other reactive oxygen species: $\mathrm{X} / \mathrm{XO}$ can reduce dioxygen univalently to $\mathrm{O}_{2}{ }^{-}$or divalently to $\mathrm{H}_{2} \mathrm{O}_{2}$. The balance between these two pathways depends on the state of reduction of the enzyme, favoring divalent reduction when the enzyme is fully reduced. Conditions such as substrate concentration, $\mathrm{pO}_{2}$, and $\mathrm{pH}$ affect the reduction state of the enzyme. Thus, it is possible that, in our experiments with the $\mathrm{X} / \mathrm{XO}$ system, gelatinases were subjected to the action of reactive oxygen species other than $\mathrm{O}_{2}^{-}$. Furthermore, addition of SOD did not block activation of MMP-2 in the presence of $\mathrm{X} / \mathrm{XO}$, which could mean that a radical other than $\mathrm{O}_{2}^{-}$may be involved. $\mathrm{H}_{2} \mathrm{O}_{2}$ generated by $\mathrm{X} / \mathrm{XO}$ or through dismutation of $\mathrm{O}_{2}{ }^{-}$could have reacted with pro-MMP-2. We tested this hypothesis and found that direct addition of $\mathrm{H}_{2} \mathrm{O}_{2}$ caused modulation of MMP-2 activity. Activation of MMP-2 at low doses of $\mathrm{H}_{2} \mathrm{O}_{2}(4 \mu \mathrm{M})$ and inactivation at higher doses $(10-50 \mu \mathrm{M})$ suggest that there may be a biphasic response to oxidant stress. High concentrations of $\mathrm{H}_{2} \mathrm{O}_{2}$ may inhibit MMP-2 enzymatic activity through mobilization of the zinc atom at the catalytic site (44). Also, higher $\mathrm{H}_{2} \mathrm{O}_{2}$ concentrations may modify the zymogen more extensively, leading to protein degradation, and could act as a regulatory mechanism for MMP activity. Similarly, the highest concentration of $\mathrm{ONOO}^{-}$that we used $(500 \mu \mathrm{M})$ seemed to inactivate pro-MMP-2. We cannot exclude the possibility that, in our in vitro conditions, the $\mathrm{OH}^{-}$radical was also formed via the $\mathrm{H}_{2} \mathrm{O}_{2}$-dependent Fenton reaction which could be supported by free metals in the culture medium.

This is, to our knowledge, the first demonstration of a protein being activated by $\mathrm{ONOO}^{-}$. $\mathrm{ONOO}^{-}$has strong oxidizing properties that may be responsible for free radical-dependent toxicity in atherosclerosis and other pathological conditions (45-47). $\mathrm{ONOO}^{-}$has the ability to nitrate tyrosine residues of proteins (48-51). Our results showed that $\mathrm{ONOO}^{-}$activates pro-MMP-2. Incubation with inactivated $\mathrm{ONOO}^{-}$, containing 
its decomposition products $\mathrm{NO}_{3}{ }^{-}$and $\mathrm{NO}_{2}{ }^{-}$, had no effect on the activation of MMP-2. It has been estimated that the average rate of $\mathrm{ONOO}^{-}$formation may reach $1 \mathrm{mM} / \mathrm{min}$ in the rat lung epithelial fluid upon stimulation of alveolar macrophages (52). The concentrations used in our study are thus within the range found in pathophysiologic states. Immunoblotting with specific antibodies showed that activation of MMP-2 was associated with almost exclusive tyrosine nitration of proteins migrating at $\sim 70 \mathrm{kD}$ (likely MMP-2) and concomitant loss of reactivity to anti-MMP-2 antibodies. It is interesting to speculate that nitration of two tyrosine residues, present within a five amino acid stretch in the hinge region between the propeptide and active domains of pro-MMP-2, could assist in unfolding of the zymogen. Using the same antinitrotyrosine antibody to stain atherosclerotic lesions, Beckman et al. (48) demonstrated an intense immunopositive reaction. Therefore it is possible that nitration of MMPs could contribute to this immunostaining pattern in atheroma. Importantly, the reaction with $\mathrm{ONOO}^{-}$ generated around activated macrophages provides a possible mechanism by which MMP activity previously detected in vulnerable areas of the atherosclerotic plaque $(1,8)$ is unleashed. NO donors used in our experiments had no effect on MMP-2 activation. A recently published study suggested that $\mathrm{NO}$ activates pro-MMP-2 (53). However, it is possible that $\mathrm{ONOO}^{-}$, rather than $\mathrm{NO}$, was directly responsible for activation of MMP-2 in that study, in which cells were simultaneously incubated in culture with cytokines, lipopolysaccharide, and $\mathrm{NO}$ donors. Under these conditions both $\mathrm{NO}$ and $\mathrm{O}_{2}^{-{ }^{-}}$may have been generated, leading to formation of $\mathrm{ONOO}^{-}$(33).

Macrophage-derived foam cells express MMP mRNA (54), produce MMP proteins $(1,28)$, and colocalize with MMP activity in human and experimental atherosclerotic plaques $(1,8)$. Shah et al. (3) showed that MMPs secreted by monocytederived macrophages may be responsible for breakdown of tissue collagen by incubating these cells, or their conditioned culture medium, with explanted atherosclerotic lesions in vitro. Since the presence of cells enhanced collagenolysis, it is possible that generation of active MMPs depended on the action of cell-released reactive oxygen species. These reactive species have a short life time and their effects would otherwise rapidly diminish in conditioned culture media.

Based on the findings of this study and of previously published reports, it appears that macrophages may be able to participate in MMP matrix degradation at several levels. These include: $(a)$ inducing MMP expression in other cells (via secretion of cytokines); (b) producing MMPs; and (c) activating latent forms of secreted MMPs (via production of reactive oxygen species). It is of note that antiprotease inhibitors (serpins) are susceptible to degradation by MMPs $(55,56)$, possibly leading to an increase in proteolytic activity in the vicinity of activated macrophages. Similarly, activated neutrophils, which generate hypochlorous acid through the action of myeloperoxidase, seem capable of autoactivating their latent collagenase (57). Since myeloperoxidase is also present in atherosclerotic vessels (58), hypochlorous acid may contribute to activation of MMPs and inactivation of serpins.

The results of this investigation provide support for a mechanism by which macrophage-derived foam cells could activate MMPs in the atherosclerotic plaque. Activation of latent MMPs by reactive oxygen species may also be relevant in other pathological conditions associated with high oxidative stress. Our observations may explain some of the benefits of antioxidant therapy $(59,60)$ and may help direct future interventions to improve plaque stability.

\section{Acknowledgments}

The authors wish to acknowledge Dr. Joe Beckman and Dr. William Stetler-Stevensen for their generous gift of antibodies, and Dr. Sampath Parthasarathy for interesting discussions.

This work was supported through a development fund from Emory University School of Medicine and funds from the Whittaker Foundation to Zorina Galis, and from National Institutes of Health grants HL-48667, DK-45215, and HL-39006, and a merit grant from the Veterans Administration to David Harrison.

\section{References}

1. Galis, Z.S., G.K. Sukhova, M.W. Lark, and P. Libby. 1994. Increased expression of matrix metalloproteinases and matrix degrading activity in vulnerable regions of human atherosclerotic plaques. J. Clin. Invest. 94:2493-2503.

2. Nikkari, S.T., K.D. O'Brien, M. Ferguson, T. Hatsukami, H.G. Welgus, C.E. Alpers, and A.W. Clowes. 1995. Interstitial collagenase (MMP-1) expression in human carotid atherosclerosis. Circulation. 92:1393-1398.

3. Shah, P.K., E. Falk, J.J. Badimon, A. Fernandez-Ortiz, A. Mailhac, G. Villareal-Levy, J.T. Fallon, J. Regnstrom, and V. Fuster. 1995. Human monocyte-derived macrophages induce collagen breakdown in fibrous caps of atherosclerotic plaques. Potential role of matrix-degrading metalloproteinases and implications for plaque rupture. Circulation. 92:1565-1569.

4. Constantinides, P. 1989. Plaque hemorrhages, their genesis and their role in supra-plaque thrombosis and atherogenesis. In Pathobiology of the Human Atherosclerotic Plaque. S. Glagov, W.P.I. Newman, and S.A. Schaffer. Springer-Verlag, New York. 393-412.

5. Falk, E., P.K. Shah, and V. Fuster. 1995. Coronary plaque disruption. Circulation. 92:657-671.

6. Richardson, P.D., M.J. Davies, and G.V. Born. 1989. Influence of plaque configuration and stress distribution on fissuring of coronary atherosclerotic plaques. Lancet. 2:941-944.

7. van der Wal, A.C., A.E. Becker, C.M. van der Loos, and P.K. Das. 1994 Site of intimal rupture or erosion of thrombosed coronary atherosclerotic plaques is characterized by an inflammatory process irrespective of the dominant plaque morphology. Circulation. 89:36-44

8. Galis, Z.S., G.K. Sukhova, and P. Libby. 1995. Microscopic localization of active proteases by in situ zymography: detection of matrix metalloproteinase activity in vascular tissue. FASEB (Fed. Am. Soc. Exp. Biol.) J. 9:974-980.

9. Lendon, C.L., M.J. Davies, G.V. Born, and P.D. Richardson. 1991. Atherosclerotic plaque caps are locally weakened when macrophage density is increased. Atherosclerosis. 87:87-90.

10. Moreno, P.R., E. Falk, I.F. Palacios, J.B. Newell, V. Fuster, and J.T. Fallon. 1994. Macrophage infiltration in acute coronary syndromes. Implications for plaque rupture. Circulation. 90:775-778.

11. Matrisian, L.M. 1994. Matrix metalloproteinase gene expression. Ann. NY Acad. Sci. 732:42-50.

12. Murphy, G., F. Willenbrock, T. Crabbe, M. O'Shea, R. Ward, S. Atkinson, J. O'Connell, and A. Docherty. 1994. Regulation of matrix metalloproteinase activity. Ann. NY Acad. Sci. 732:31-41.

13. Okada, Y., T. Morodomi, J.J. Enghild, K. Suzuki, A. Yasui, I. Nakanishi, G. Salvesen, and H. Nagase. 1990. Matrix metalloproteinase 2 from human rheumatoid synovial fibroblasts. Purification and activation of the precursor and enzymic properties. Eur. J. Biochem. 194:721-730.

14. Nagase, H., J.J. Enghild, K. Suzuki, and G. Salvesen. 1990. Stepwise activation mechanisms of the precursor of matrix metalloproteinase 3 (stromelysin) by proteinases and (4-aminophenyl)mercuric acetate. Biochemistry. 29: 5783-5789.

15. Galis, Z.S., R. Kranzhöfer, and P. Libby. 1995. Thrombin promotes activation of matrix metalloproteinase-2 (MMP-2) produced by cultured smooth muscle cells. FASEB (Fed. Am. Soc. Exp. Biol.) J. 9:A413.

16. Van Wart, H.E., and H. Birkedal-Hansen. 1990. The cysteine switch: a principle of regulation of metalloproteinase activity with potential applicability to the entire matrix metalloproteinase gene family. Proc. Natl. Acad. Sci. USA. 87:5578-5582.

17. Suzuki, K., J.J. Enghild, T. Morodomi, G. Salvesen, and H. Nagase. 1990. Mechanisms of activation of tissue procollagenase by matrix metalloproteinase 3 (stromelysin). Biochemistry. 29:10261-10270.

18. Griendling, K., J.D. Ollerenshaw, C.A. Minieri, and R.W. Alexander. 1994. Angiotensin II stimulates NADH and NADPH activity in cultured vascular smooth muscle cells. Circ. Res. 74:1141-1148.

19. Matsubara, T., and M. Ziff. 1986. Superoxide anion release by human endothelial cells: synergism between a phorbol ester and a calcium ionophore. J. Cell. Physiol. 127:207-210. 
20. Mohazzab, K.M., P.M. Kaminski, and M.S. Wolin. 1994. NADH oxidoreductase is a major source of superoxide anion in bovine coronary artery endothelium. Am. J. Physiol. 266:H2568-H2572.

21. Segal, A.W., and A. Abo. 1993. The biochemical basis of the NADPH oxidase of phagocytes. Trends Biochem. Sci. 18:43-47.

22. Ohara, Y., T.E. Peterson, and D.G. Harrison. 1993. Hypercholesterolemia increases endothelial superoxide anion production. J. Clin. Invest. 91: 2546-2551.

23. Rajagopalan, S., S. Kurz, T. Münzel, M. Tarpey, B. Freeman, K. Griendling, and D. Harrison. 1996. Angiotensin II-mediated hypertension in the rat increases vascular superoxide production via membrane NADH/NADPH oxidase activation. Contribution to alterations of vasomotor tone. J. Clin. Invest. 97:1916-1923.

24. Tesfamariam, B. 1994. Free radicals in diabetic endothelial cell dysfunction. Free Radical Biol. Med. 16:383-391.

25. Giugliano, D., A. Ceriello, and G. Paolisso. 1995. Diabetes mellitus, hypertension, and cardiovascular disease: which role for oxidative stress? Metab. Clin. Exp. 44:363-368.

26. Schwartz, C.J., J.J. Ghidoni, J.L. Kelley, E.A. Sprague, A.J. Valente, and C.A. Suenram. 1985. Evolution of foam cells in subcutaneous rabbit carrageenan granulomas. I. Light-microscopic and ultrastructural study. Am. J. Pathol. 118:134-150.

27. Bell, F.P., and R.G. Schaub. 1989. Comparison of lipid accumulation and metabolism in carrageenan-induced granulomas to aorta and blood monocytes of normal and cholesterol-fed rabbits. Exp. Mol. Pathol. 50:327-336.

28. Galis, Z.S., G.K. Sukhova, R. Kranzhöfer, S. Clark, and P. Libby. 1995. Macrophage foam cells from experimental atheroma constitutively produce matrix-degrading proteinases. Proc. Natl. Acad. Sci. USA. 92:402-406.

29. Rosenfeld, M.E., J.C. Khoo, E. Miller, S. Parthasarathy, W. Palinski, and J.L. Witztum. 1991. Macrophage-derived foam cells freshly isolated from rabbit atherosclerotic lesions degrade modified lipoproteins, promote oxidation of low-density lipoproteins, and contain oxidation-specific lipid-protein adducts. J. Clin. Invest. 87:90-99.

30. Gyllenhammar, H. 1987. Lucigenin chemiluminescence in the assessment of neutrophil superoxide production. J. Immunol. Methods. 97:209-213.

31. Hecker, M., W.C. Sessa, H.J. Harris, E.E. Anggard, and J.R. Vane. 1990. The metabolism of L-arginine and its significance for the biosynthesis of endothelium-derived relaxing factor: cultured endothelial cells recycle L-citrulline to L-arginine. Proc. Natl. Acad. Sci. USA. 87:8612-8616.

32. Royall, J.A., and H. Ischiropoulos. 1993. Evaluation of 2',7'-dichlorofluorescin and dihydrorhodamine 123 as fluorescent probes for intracellular $\mathrm{H}_{2} \mathrm{O}_{2}$ in cultured endothelial cells. Arch. Biochem. Biophys. 302:348-355.

33. Huie, R.E., and S. Padmaja. 1993. The reaction of NO with superoxide. Free Radical Res. Commun. 18:195-199.

34. Strongin, A.Y., I. Collier, G. Bannikov, B.L. Marmer, G.A. Grant, and G.I. Goldberg. 1995. Mechanism of cell surface activation of 72-kDa type IV collagenase. Isolation of the activated form of the membrane metalloprotease. J. Biol. Chem. 270:5331-5338.

35. Cao, J., H. Sato, T. Takino, and M. Seiki. 1995. The C-terminal region of membrane type matrix metalloproteinase is a functional transmembrane domain required for pro-gelatinase A activation. J. Biol. Chem. 270:801-805.

36. Galis, Z.S., M. Muszynski, G.K. Sukhova, E. Simon-Morrissey, E.N. Unemori, M.W. Lark, E. Amento, and P. Libby. 1994. Cytokine-stimulated human vascular smooth muscle cells synthesize a complement of enzymes required for extracellular matrix digestion. Circ. Res. 75:181-189.

37. Hanemaaijer, R., P. Koolwijk, L. le Clercq, W.J. de Vree, and V.W. van Hinsbergh. 1993. Regulation of matrix metalloproteinase expression in human vein and microvascular endothelial cells. Effects of tumour necrosis factor alpha, interleukin 1 and phorbol ester. Biochem. J. 296:803-809.

38. Southgate, K.M., M. Davies, R.F. Booth, and A.C. Newby. 1992. Involvement of extracellular-matrix-degrading metalloproteinases in rabbit aortic smooth-muscle cell proliferation. Biochem. J. 288:93-99.

39. Pauly, R.R., A. Passaniti, C. Bilato, R. Monticone, L. Cheng, N. Papadopoulos, Y.A. Gluzband, L. Smith, C. Weinstein, E.G. Lakatta, and M.T. Crow. 1994. Migration of cultured vascular smooth muscle cells through a base- ment membrane barrier requires type IV collagenase activity and is inhibited by cellular differentiation. Circ. Res. 75:41-54.

40. Bendeck, M.P., N. Zempo, A.W. Clowes, R.E. Galardy, and M.A. Reidy 1994. Smooth muscle cell migration and matrix metalloproteinase expression after arterial injury in the rat. Circ. Res. 75:539-545.

41. Zempo, N., R.D. Kenagy, Y.P.T. Au, M. Bendeck, M.M. Clowes, M.A Reidy, and A.W. Clowes. 1994. Matrix metalloproteinases of vascular wall cells are increased in balloon-injured rat carotid artery. J. Vasc. Surg. 20:209-217.

42. Welgus, H.G., R.M. Senior, W.C. Parks, A.J. Kahn, T.J. Ley, S.D. Shapiro, and E.J. Campbell. 1992. Neutral proteinase expression by human mononuclear phagocytes: a prominent role of cellular differentiation. Matrix Suppl. $1: 363-367$.

43. Brown, D.L., M.S. Hibbs, M. Kearney, C. Loushin, and J.M. Isner. 1995. Identification of $92-\mathrm{kD}$ gelatinase in human coronary atherosclerotic lesions. Association of active enzyme synthesis with unstable angina. Circulation. 91: 2125-2131.

44. Fliss, H., and M. Menard. 1992. Oxidant-induced mobilization of zinc from metallothionein. Arch. Biochem. Biophys. 293:195-199.

45. Radi, R., J.S. Beckman, K.M. Bush, and B.A. Freeman. 1991. Peroxynitrite-induced membrane lipid peroxidation: the cytotoxic potential of superoxide and nitric oxide. Arch. Biochem. Biophys. 288:481-487.

46. Radi, R., J.S. Beckman, K.M. Bush, and B.A. Freeman. 1991. Peroxynitrite oxidation of sulfhydryls. The cytotoxic potential of superoxide and nitric oxide. J. Biol. Chem. 266:4244-4250.

47. Beckman, J.S., T.W. Beckman, J. Chen, P.A. Marshall, and B.A. Freeman. 1990. Apparent hydroxyl radical production by peroxynitrite: implications for endothelial injury from nitric oxide and superoxide. Proc. Natl. Acad. Sci. USA. 87:1620-1624.

48. Beckman, J.S., Y.Z. Ye, P.G. Anderson, J. Chen, M.A. Accavitti, M.M. Tarpey, and C.R. White. 1994. Extensive nitration of protein tyrosines in human atherosclerosis detected by immunohistochemistry. Biol. Chem. Hoppe Seyler. 375:81-88.

49. Haddad, I.Y., G. Pataki, P. Hu, C. Galliani, J.S. Beckman, and S. Matalon. 1994. Quantitation of nitrotyrosine levels in lung sections of patients and animals with acute lung injury. J. Clin. Invest. 94:2407-2413.

50. Ischiropoulos, H., and A.B. al-Mehdi. 1995. Peroxynitrite-mediated oxidative protein modifications. FEBS Lett. 364:279-282.

51. van der Vliet, A., J.P. Eiserich, C.A. O'Neill, B. Halliwell, and C.E. Cross. 1995. Tyrosine modification by reactive nitrogen species: a closer look. Arch. Biochem. Biophys. 319:341-349.

52. Ischiropoulos, H., L. Zhu, and J.S. Beckman. 1992. Peroxynitrite formation from macrophage-derived nitric oxide. Arch. Biochem. Biophys. 298:446-451.

53. Trachtman, H., S. Futterweit, P. Garg, K. Reddy, and P.C. Singhal. 1996. Nitric oxide stimulates the activity of a 72-kDa neutral matrix metalloproteinase in cultured rat mesangial cells. Biochem. Biophys. Res. Commun. 218:704-708.

54. Henney, A.M., P.R. Wakeley, M.J. Davies, K. Foster, R. Hembry, G. Murphy, and S. Humphries. 1991. Localization of stromelysin gene expression in atherosclerotic plaques by in situ hybridization. Proc. Natl. Acad. Sci. USA. 88:8154-8158.

55. Desrochers, P.E., J.J. Jeffrey, and S.J. Weiss. 1991. Interstitial collagenase (matrix metalloproteinase-1) expresses serpinase activity. J. Clin. Invest. $87: 2258-2265$

56. Wallaert, B., C. Aerts, B. Gressier, P. Gosset, and C. Voisin. 1993. Oxidative inactivation of alpha 1-proteinase inhibitor by alveolar epithelial type II cells. J. Appl. Physiol. 75:2376-2382.

57. Weiss, S.J., G. Peppin, X. Ortiz, C. Ragsdale, and S.T. Test. 1985. Oxidative autoactivation of latent collagenase by human neutrophils. Science (Wash. DC). 227:747-749.

58. Daugherty, A., J.L. Dunn, D.L. Rateri, and J.W. Heinecke. 1994. Myeloperoxidase, a catalyst for lipoprotein oxidation, is expressed in human atherosclerotic lesions. J. Clin. Invest. 94:437-444.

59. Gaziano, J.M. 1994. Antioxidant vitamins and coronary artery disease risk. Am. J. Med. 97:18S-21S; Discussion 22S-28S.

60. Tanswell, A.K., and B.A. Freeman. 1995. Antioxidant therapy in critical care medicine. New Horiz. 3:330-341. 